Supplementary data

of

\title{
Glycopolymer Nanoparticles with On-Demand Glucose-Responsive Insulin Delivery and Low-Hypoglycemia Risks for Type 1 Diabetic
}

\section{Treatment}

Yun Fu ${ }^{1,2}$, Yuxin Sun ${ }^{1,2}$, Meng Chen ${ }^{1,2}$, Wenqian Xing ${ }^{1,2}$, Yufang Xu ${ }^{1,2}$, Xuhong Qian ${ }^{1,2}$ and Weiping $\mathrm{Zhu}^{1,2, *}$

1 State Key Laboratory of Bioreactor Engineering, Shanghai Key Laboratory of Chemical

Biology, School of Pharmacy, East China University of Science and Technology, 130 Meilong Road, Shanghai 200237, China

2 Shanghai Frontiers Science Center of Optogenetic Techniques for Cell Metabolism, School of Pharmacy, East China University of Science and Technology, 130 Meilong Road, Shanghai 200237, China

* Correspondence should be addressed to whom.

E-mail address: wpzhu@ecust.edu.cn (W. Zhu). 
Materials. Ethanolamine hydrochloride (98 \%), hydroquinone (99 \%), Glucono- $\delta$-Lactone (99\%), triethylamine (99\%), ethyl acetate (99\%), isopropyl alcohol (99.9\%) were purchased from Shanghai Titan Technology Co., Ltd. 4-carboxy-3-fluorobenzenic acid (FPBA) (98 \%), 1(3-dimethylaminopropyl)-3-ethylcarbondiimide hydrochloride $\quad$ (EDCI) $\quad(95 \%), \quad \mathrm{N}-$ hydroxysuccinimide (NHS) (98 \%) were purchased from Shanghai Macklin Co., Ltd. 2-(dodecyl trithiocarbonate)-2-methylpropionic acid (DDMAT) (97\%), 2,2'-Azobis(2-methylpropionitrile) (AIBN) (98\%), N-Boc-ethylenediamine (98\%), acryloyl chloride (96\%), methyl acryloyl chloride (90 \%) were purchased from Shanghai Aladdin Biochemical Technology Co., Ltd. Sodium bicarbonate, hydrochloric acid (36.0 \% 38.0 \%) purchased from Sinopharm Chemical Reagent Co., Ltd. Dialysis bag (1000 kDa) was purchased from Nantong Feiyu Biotechnology Co., Ltd.

Characterization. ${ }^{1} \mathrm{H}$ NMR spectra of all the chemical compound were characterized on Brucker Avance $400 \mathrm{MHZ}$ spectrometer. Hydrodynamic diameter and Zeta potential were measured by Malvern Mastersizer 2000. Transmission Electron Microscopy was measured by JEOL JEM-2100 (200 kV). Gel Permeation Chromatography (GPC) analysis was measured by Agilent PL-GPC50 \& Agilent PL-GPC220. 


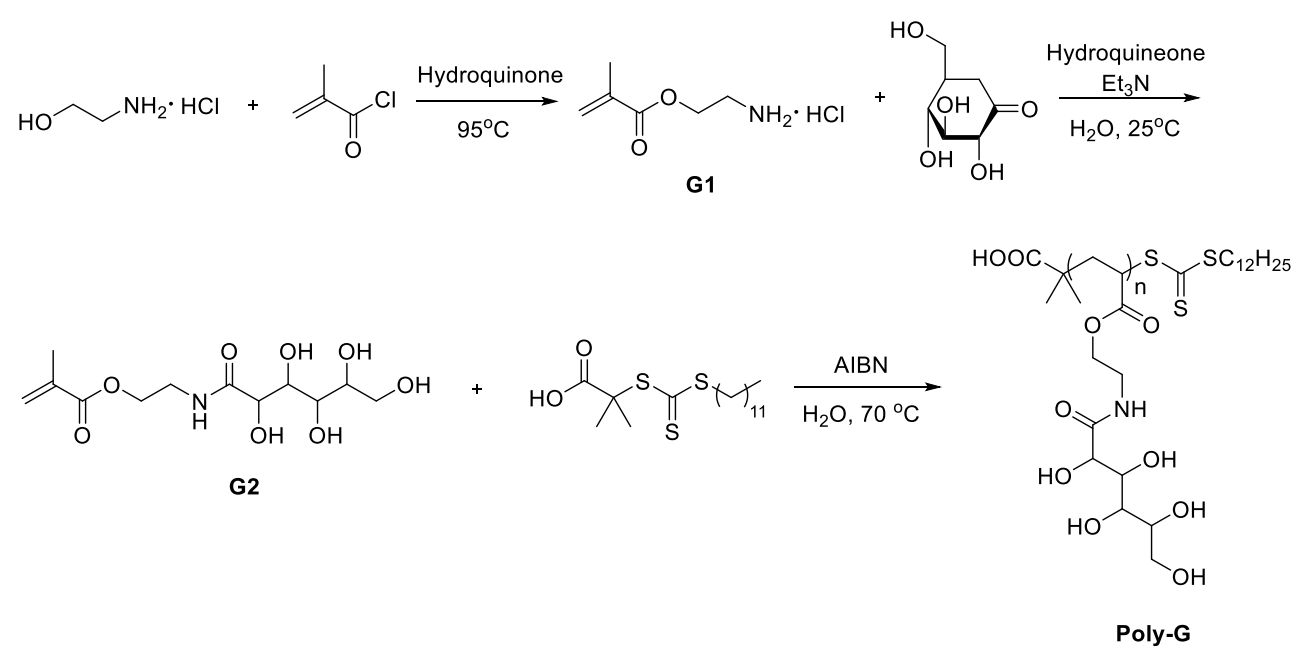

Figure S1. Synthesis route of poly-G

The synthesis of G1. 2-Aminoethanol hydrochloride $(32.50 \mathrm{~g}, 0.335 \mathrm{mmol})$ and hydroquinone (0.25 g, 2,27 mmol) were added into a $500 \mathrm{~mL}$ flask, which was set on a $95{ }^{\circ} \mathrm{C}$ oil bath with stirring. After that, methacrylchloride $(50 \mathrm{~mL}, 0.48 \mathrm{~mol})$ were added dropwise in $30 \mathrm{~min}$. The reaction was continued for $1 \mathrm{~h}$. Then, the temperature was lowered down to $60{ }^{\circ} \mathrm{C}$ and added with $200 \mathrm{~mL}$ ethyl acetate. The precipitates were filtrated and recrystallized (ethyl acetate/ isopropanol = 7:3, v/v) to obtain G1 $(73.4 \%) .{ }^{1} \mathrm{H}$ NMR $\left(400 \mathrm{MHz}, \mathrm{H}_{2} \mathrm{O}-d \sigma\right): \delta 6.13(\mathrm{~s}, 1 \mathrm{H}), 5.71$ (s, 1H), $4.45-4.29(\mathrm{~m}, 2 \mathrm{H}), 3.38-3.26(\mathrm{~m}, 2 \mathrm{H}), 1.87(\mathrm{~s}, 3 \mathrm{H})$.

The synthesis of G2. G2 (8.00 g, $48.30 \mathrm{mmol})$ and glucosactone $(5.0 \mathrm{~g}, 28.1 \mathrm{mmol})$ were added to a $250 \mathrm{~mL}$ flask, and was added further added with $50 \mathrm{~mL}$ deionized water and triethylamine (6.5 mL, $46.54 \mathrm{mmol})$. The reaction was set at room temperature and continued for $5 \mathrm{~h}$. After that, the solvent was moved and added with excess amount of isopropanol. The precipitates were washed with isopropanol and dried to obtain G2 (40.5\%). ${ }^{1} \mathrm{H}$ NMR (400 MHz, DMSO-d6): $\delta$ $7.82(\mathrm{t}, J=5.8 \mathrm{~Hz}, 1 \mathrm{H}), 6.05(\mathrm{~s}, 1 \mathrm{H}), 5.67(\mathrm{~s}, 1 \mathrm{H}), 5.40(\mathrm{~d}, J=5.0 \mathrm{~Hz}, 1 \mathrm{H}), 4.53(\mathrm{~d}, J=4.0 \mathrm{~Hz}$, 1H), $4.46(\mathrm{~d}, J=4.7 \mathrm{~Hz}, 1 \mathrm{H}), 4.39(\mathrm{~d}, J=7.2 \mathrm{~Hz}, 1 \mathrm{H}), 4.32(\mathrm{t}, J=5.6 \mathrm{~Hz}, 1 \mathrm{H}), 4.10(\mathrm{t}, J=5.8$ 
$\mathrm{Hz}, 2 \mathrm{H}), 4.00(\mathrm{t}, J=4.3 \mathrm{~Hz}, 1 \mathrm{H}), 3.91(\mathrm{~d}, J=5.2 \mathrm{~Hz}, 1 \mathrm{H}), 3.57(\mathrm{dd}, J=10.9,5.8 \mathrm{~Hz}, 1 \mathrm{H}), 3.51-$ $3.33(\mathrm{~m}, 5 \mathrm{H}), 1.88(\mathrm{~s}, 3 \mathrm{H})$

The synthesis of poly-G. G2 (307.3 mg, $1.00 \mathrm{mmol})$, DDMAT (3.65 mg, $0.01 \mathrm{mmol})$, AIBN $(0.1644 \mathrm{mg}, 0.001 \mathrm{mmol})$ and $1 \mathrm{~mL}$ deionized water were added to a $25 \mathrm{~mL}$ flask. After deoxidized for $30 \mathrm{~min}$, the flask was set in a $70{ }^{\circ} \mathrm{C}$ oil bath. The reaction was continued for $12 \mathrm{~h}$. The product was precipitated in methanol and redissolved in water. This process was carried out for several times. After lyophilization, poly-G was obtained as white solid (48.6\%).

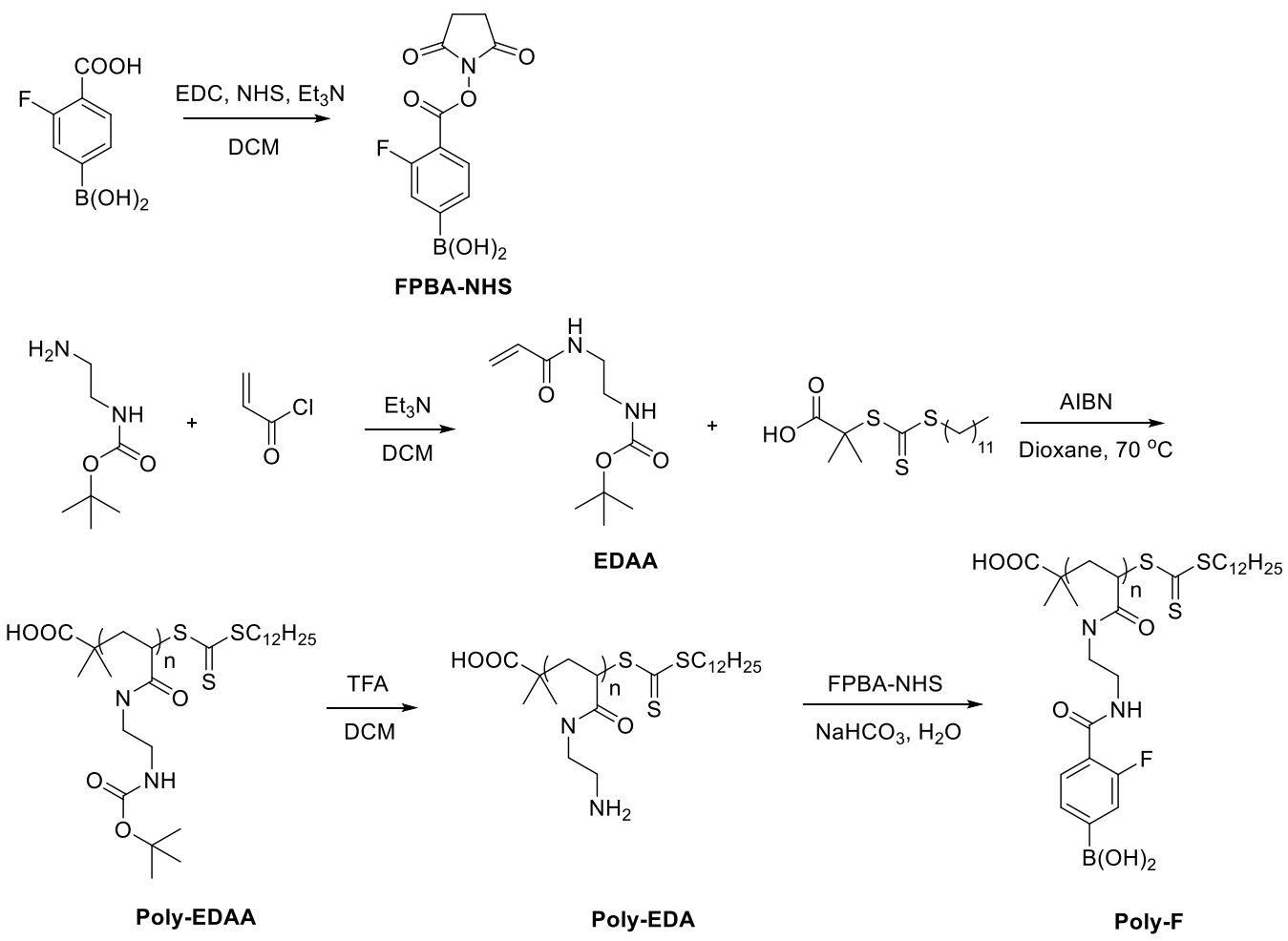

Figure S2. Synthesis route of poly-F

The synthesis of FPBA-NHS. 4-carboxy-3-fluorobenzenic acid (FPBA), NHS (2.0 g, 17.38 $\mathrm{mmol})$ and $50 \mathrm{~mL}$ anhydrous DMF were added in to a $250 \mathrm{~mL}$ flask. Then, EDCI $(3.0 \mathrm{~g}, 15.65$ mmol $)$ and triethylamine $(2.5 \mathrm{~mL}, 17.90 \mathrm{mmol})$ was added and the reaction was continued for 16 
$\mathrm{h}$ at room temperature. Then, the solvent was evaporated to about $5 \mathrm{~mL}$ left and added with dichloromethane and $0.5 \mathrm{M} \mathrm{HCl}$ solution. The precipitates were filtrated and washed with several times to obtain FPBA-NHS (70.49\%). ${ }^{1} \mathrm{H}$ NMR (400 MHz, DMSO- $\left.d_{6}\right): \delta 8.03$ (t, $J=7.4$ $\mathrm{Hz}, 1 \mathrm{H}), 7.81(\mathrm{~d}, J=8.0 \mathrm{~Hz}, 1 \mathrm{H}), 7.77(\mathrm{~d}, J=11.8 \mathrm{~Hz}, 1 \mathrm{H}), 2.90(\mathrm{~s}, 4 \mathrm{H})$. The synthesis of F1. NBoc-N-methylethylenediamine $(5.0 \mathrm{~g}, 31.21 \mathrm{mmol})$, triethylamine $(8.68 \mathrm{~mL}, 62.15 \mathrm{mmol})$ and $50 \mathrm{~mL}$ dichloromethane were added to a $250 \mathrm{~mL}$ flask. Then, acryloyl chloride $(5.07 \mathrm{~mL}, 62.40$ mmol) was added dropwise into the reaction in 30 min under ice bath. The reaction was then continued for 30 min under room temperature. After that, saturated $\mathrm{NH}_{4} \mathrm{Cl}$ solution was used to quench the reaction and the product was extracted and purified by column chromatography $(\mathrm{PE} / \mathrm{EA}=5: 1, \mathrm{v} / \mathrm{v})$ to obtain F1 (76.53 \%). ${ }^{1} \mathrm{H}$ NMR (400 MHz, $\left.\mathrm{CDCl}_{3}-d 6\right): \delta 6.62(\mathrm{~s}, 1 \mathrm{H}), 6.20$ (d, $J=17.0 \mathrm{~Hz}, 1 \mathrm{H}), 6.05(\mathrm{dd}, J=17.0,10.2 \mathrm{~Hz}, 1 \mathrm{H}), 5.57$ (d, $J=10.3 \mathrm{~Hz}, 1 \mathrm{H}), 5.07(\mathrm{~s}, 1 \mathrm{H})$, $3.37(\mathrm{dd}, J=10.8,5.3 \mathrm{~Hz}, 2 \mathrm{H}), 3.31-3.16(\mathrm{~m}, 2 \mathrm{H}), 1.37$ (s, 9H).

The synthesis of F2. F1 (321.4 mg, $2.25 \mathrm{mmol}$ ), DDMAT (5.133 mg, $0.015 \mathrm{mmol}$ ), AIBN (0.2314 mg, $0.0015 \mathrm{mmol})$ and $1.5 \mathrm{~mL}$ 1,4-dioxane were added to a $25 \mathrm{~mL}$ flask. After deoxidized for $30 \mathrm{~min}$, the flask was set in a $70^{\circ} \mathrm{C}$ oil bath. The reaction was continued for $12 \mathrm{~h}$. The product was precipitated in hexane and redissolved in 1,4-dioxane. This process was carried out for several times. After lyophilization, F2 was obtained as white solid (48.2 \%).

The synthesis of F3. F2 (1.0 g), $20 \mathrm{~mL}$ dichloromethane and $5 \mathrm{~mL}$ trifluoroacetic acid were added into a $25 \mathrm{~mL}$ flask and the reaction was carried out under room temperature. After $6 \mathrm{~h}$, the solvent was evaporated and the product was dialyzed against deionized water in the dialysis bag $(1000 \mathrm{kDa})$ for $72 \mathrm{~h}$. The deionized water was changed every $12 \mathrm{~h}$. After that, F3 was obtained by lyophilization (39.0\%). 
The synthesis of poly-F. F3 $(0.15 \mathrm{~g})$ and $10 \mathrm{~mL}$ deionized water was added into a $25 \mathrm{~mL}$ flask. Then, FPBA-NHS (0.41 g, $1.46 \mathrm{mmol})$ was dissolved in $2 \mathrm{~mL}$ DMSO and added to the flask. The $\mathrm{pH}$ was maintained around 7.2. After $2 \mathrm{~h}$, the solution was dialyzed against deionized water in the dialysis bag $(1000 \mathrm{kDa})$ for $72 \mathrm{~h}$. The deionized water was changed every $12 \mathrm{~h}$. After that, poly-F was obtained by lyophilization ( $85.4 \%)$. 


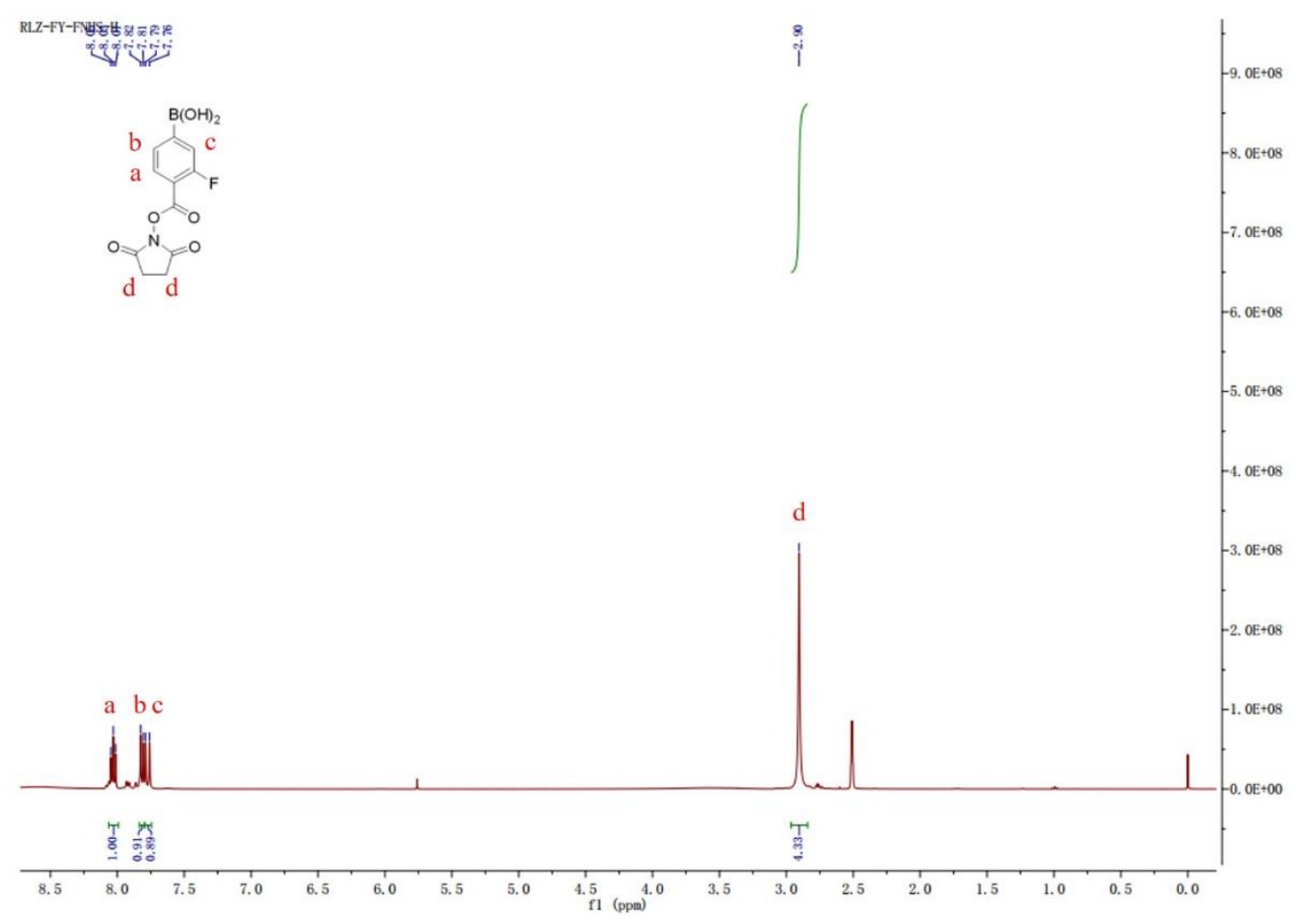

Figure S3. ${ }^{1} \mathrm{H}$ NMR of FPBA-NHS. 


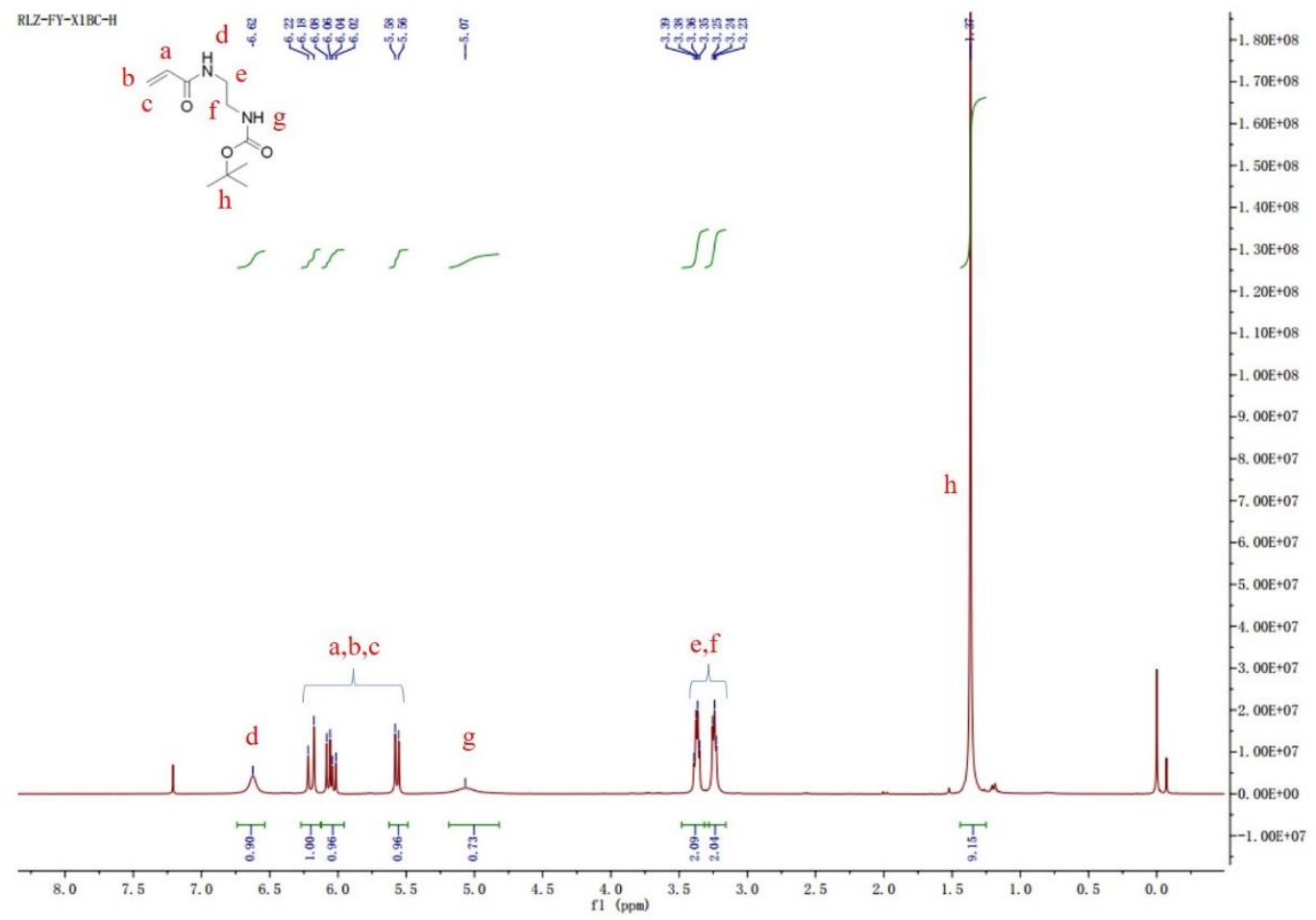

Figure S4. ${ }^{1} \mathrm{H}$ NMR of EDAA. 


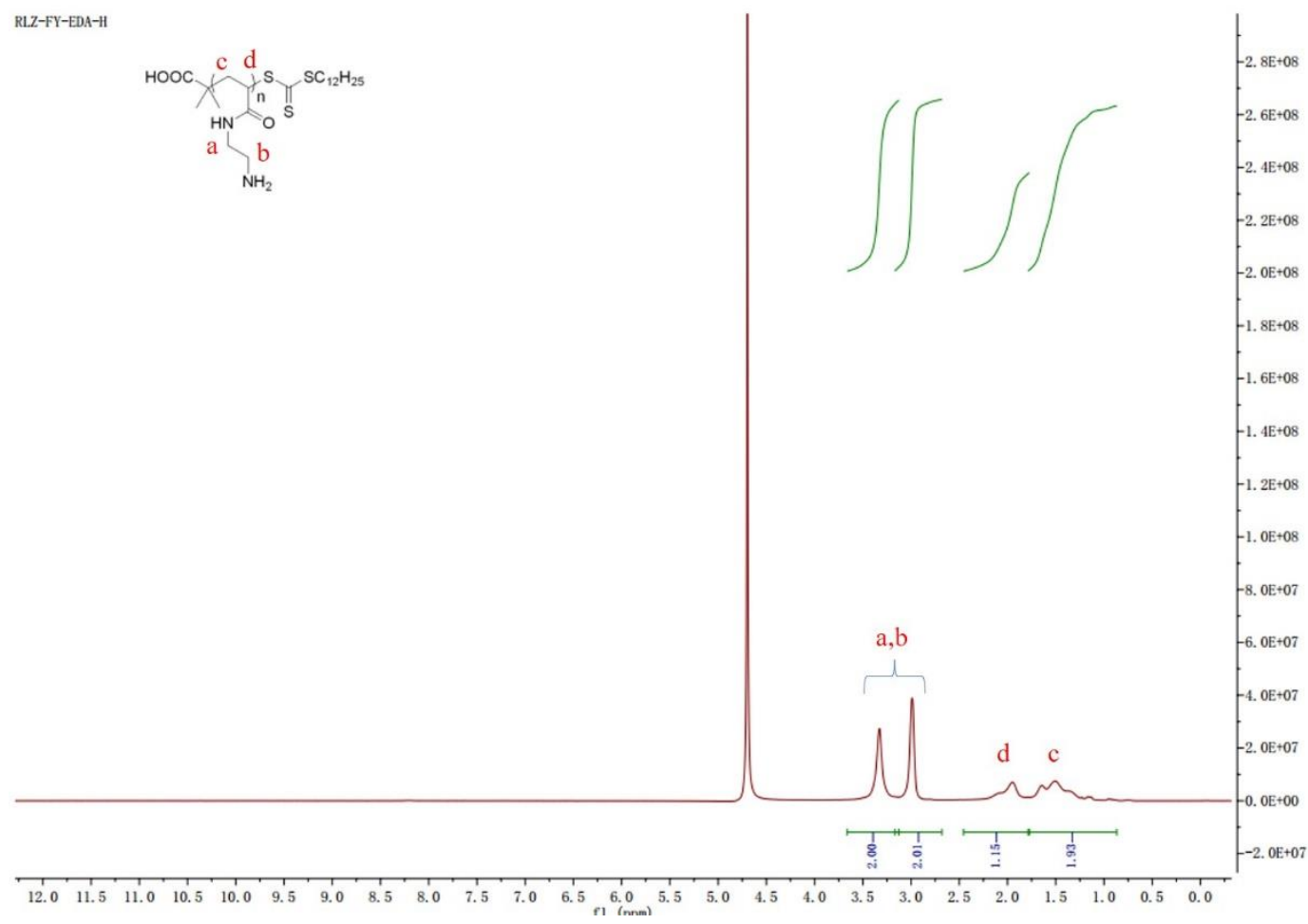

Figure S5. ${ }^{1} \mathrm{H}$ NMR of poly-EDA. 


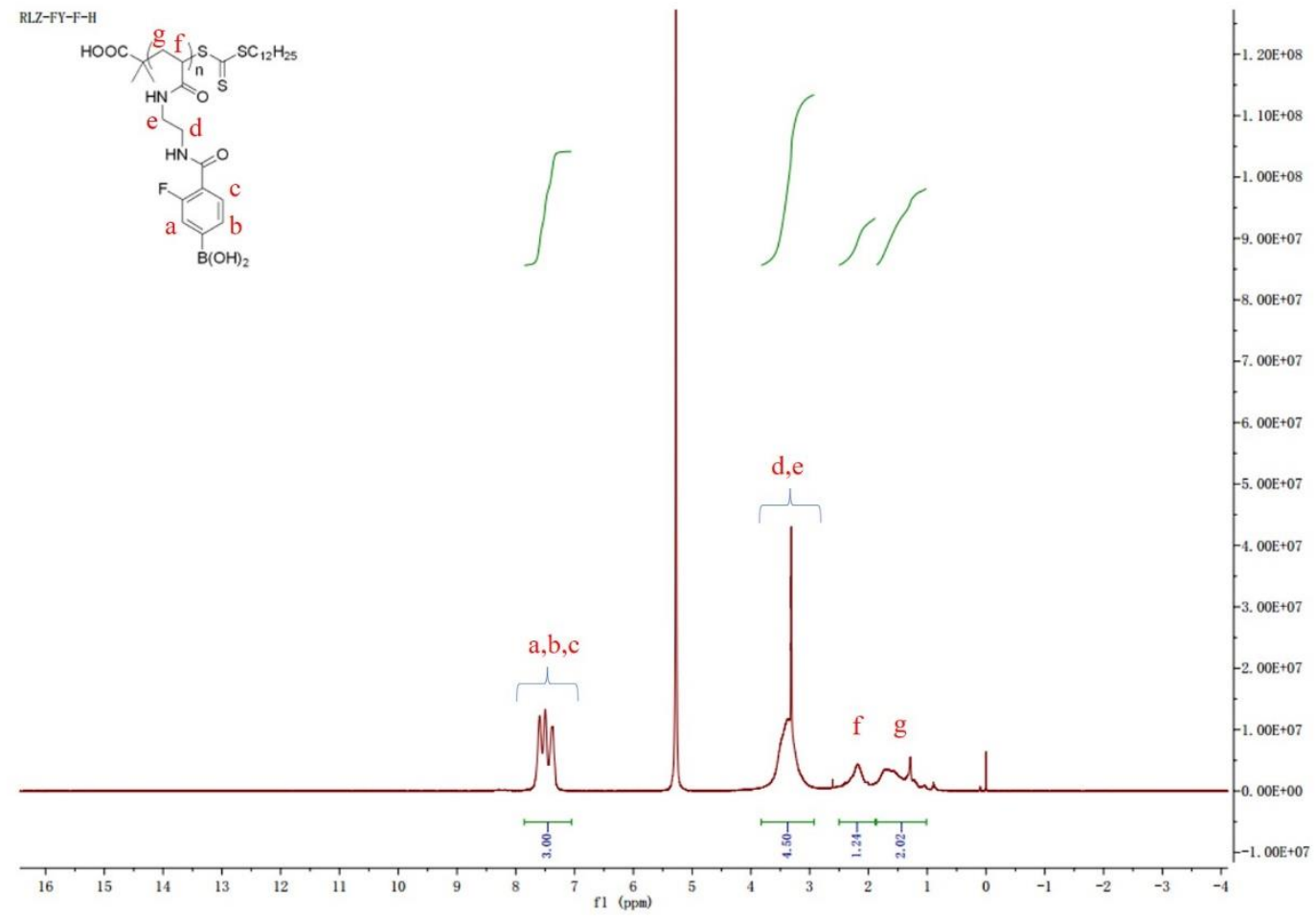

Figure S6. ${ }^{1} \mathrm{H}$ NMR of poly-F. 


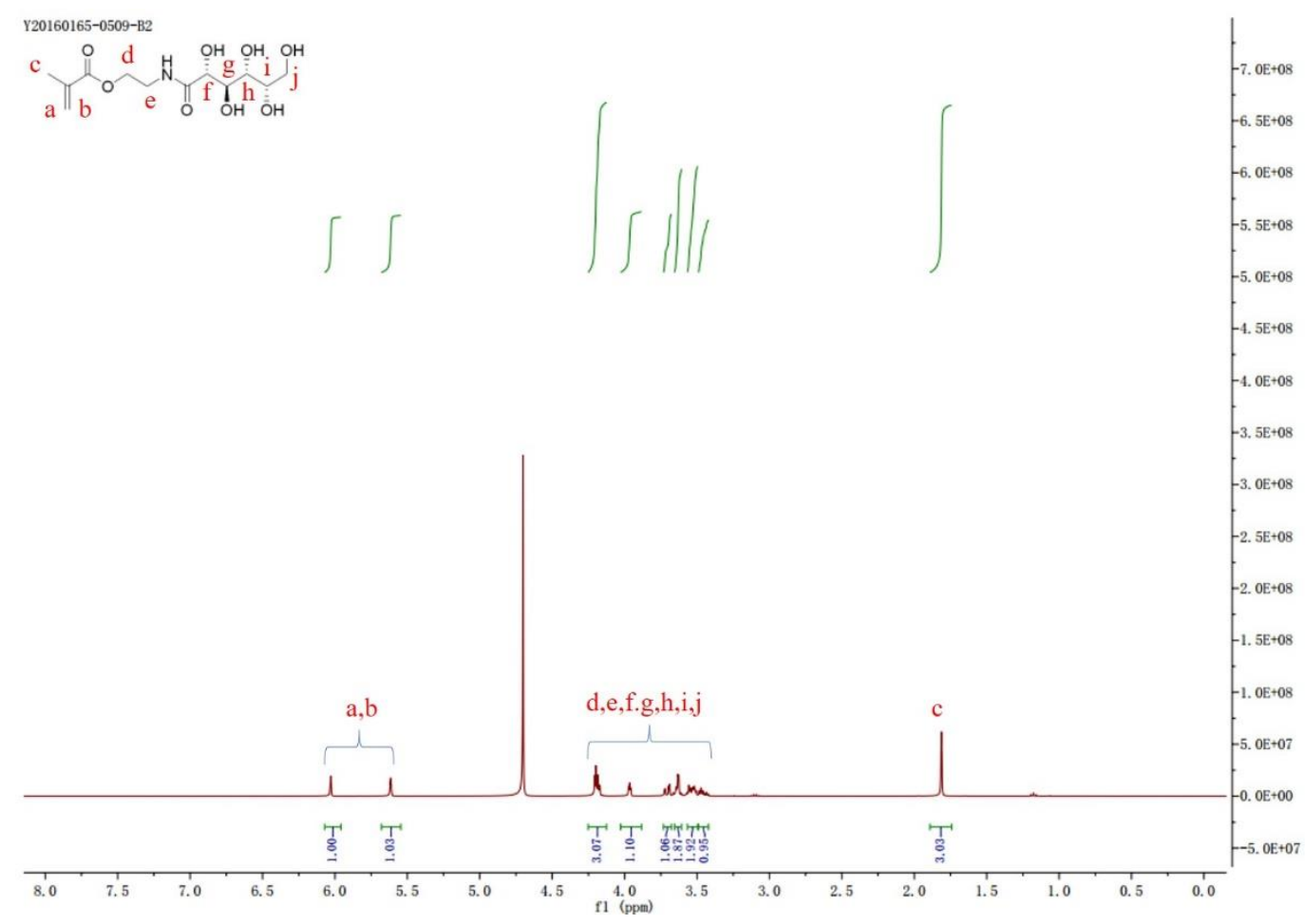

Figure S7. ${ }^{1} \mathrm{H}$ NMR of G2. 


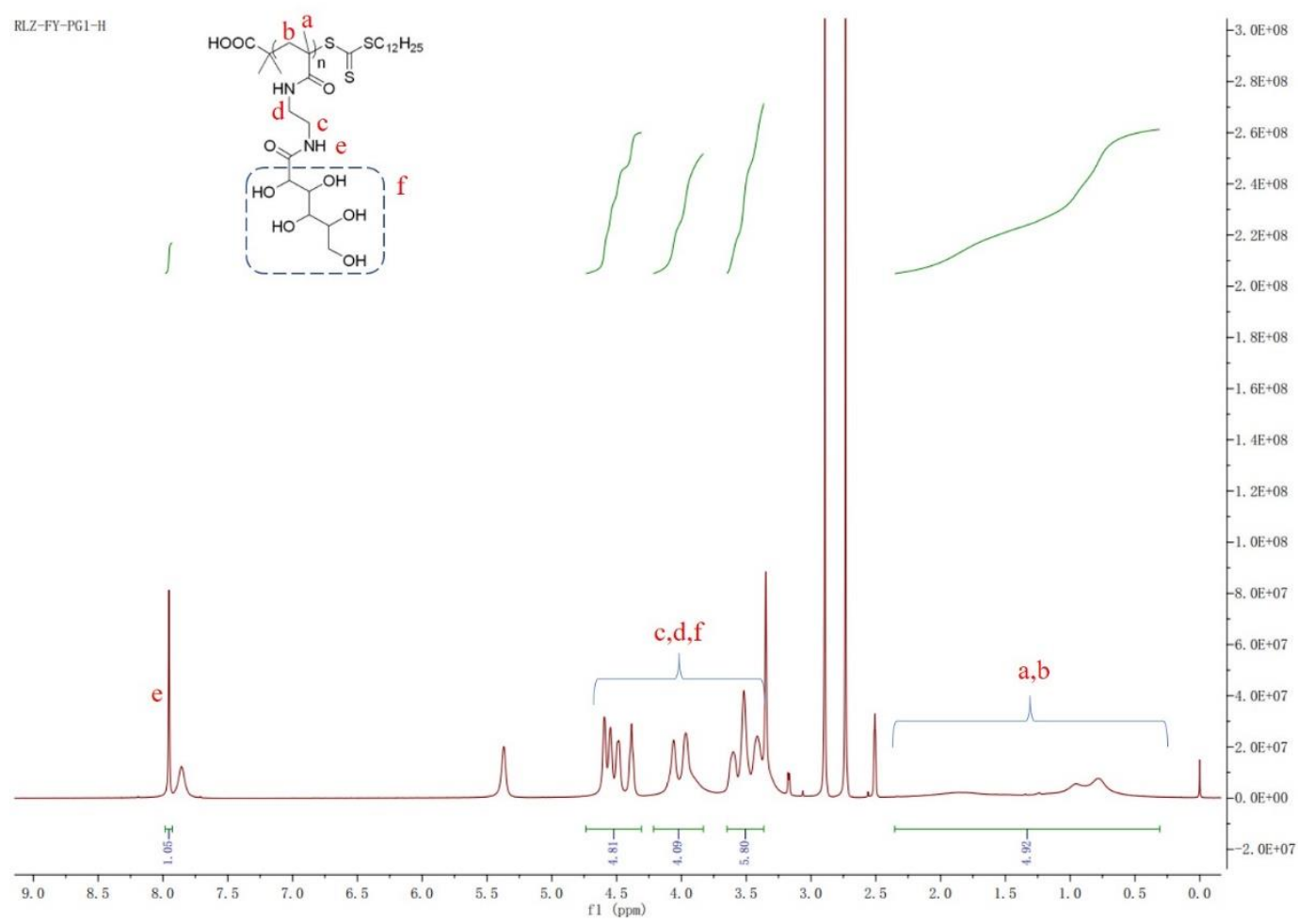

Figure S8. ${ }^{1} \mathrm{H}$ NMR of poly-G 
Table S1. GPC analysis of poly-F and poly-G.

\begin{tabular}{ccccc}
\hline & Mp & Mn & Mw & PD \\
\hline poly-F & 95637 & 57442 & 81482 & 1.41851 \\
poly-G & 71591 & 46599 & 78160 & 1.67729 \\
\hline
\end{tabular}

Table S2. Loading capacity and loading efficiency of the nanoparticles

\begin{tabular}{lcc}
\hline & Loading capacity & Loading efficiency \\
\hline poly-FG2@insulin & $12.68 \%$ & $17.66 \%$ \\
poly-FG4@insulin & $10.43 \%$ & $23.86 \%$ \\
poly-FG6@insulin & $8.41 \%$ & $28.39 \%$ \\
\hline
\end{tabular}

Loading capacity $=$ The amount of insulin loaded $/$ The weight of the complex

Loading efficiency $=$ The amount of insulin loaded $/$ The amount of insulin used 


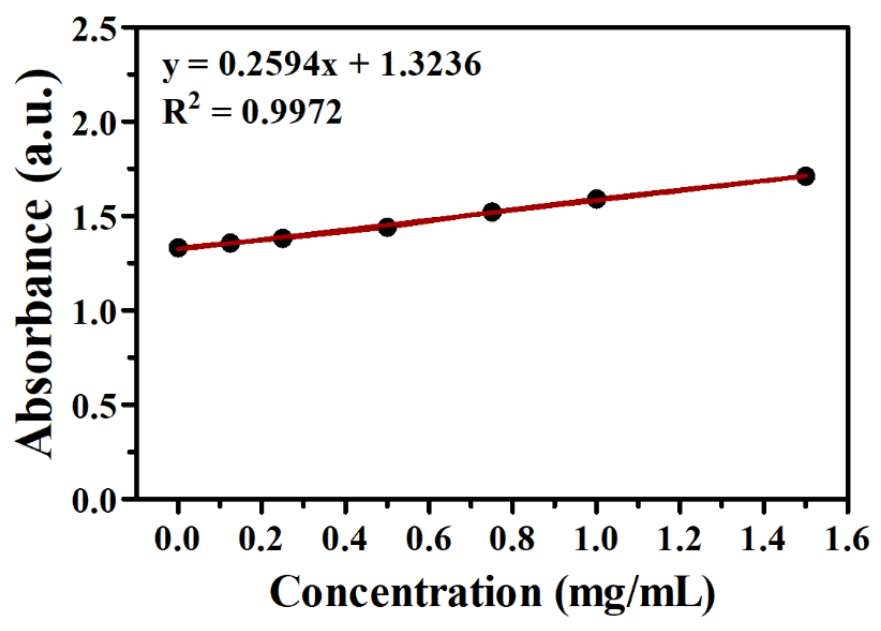

Figure S9. Insulin standard curve 

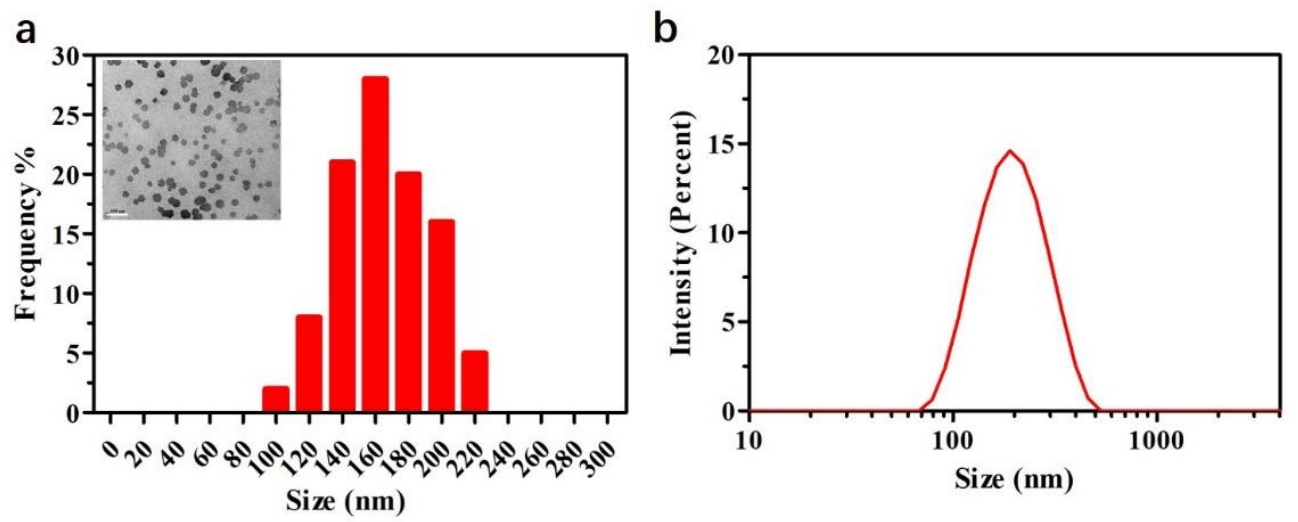

Figure S10. Size distribution of poly-FG4 by (a) TEM, scale bar $=500 \mathrm{~nm}$. (b) DLS analysis.

Table S3. Diameters changes of poly-FG4 in PBS solutions (Day 1 and Day7)

\begin{tabular}{ccc}
\hline poly-FG4 & $\mathbf{1}$ & $\mathbf{7}$ \\
\hline Average Size (nm) & $197.3 \pm 1.6$ & $201.7 \pm 3.0$ \\
\hline
\end{tabular}


(a)

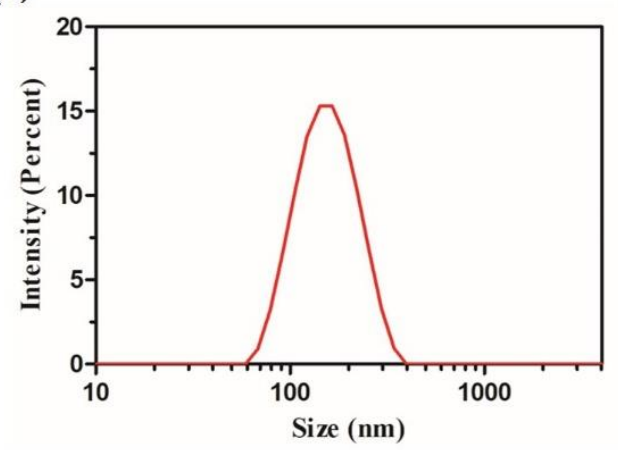

(b)

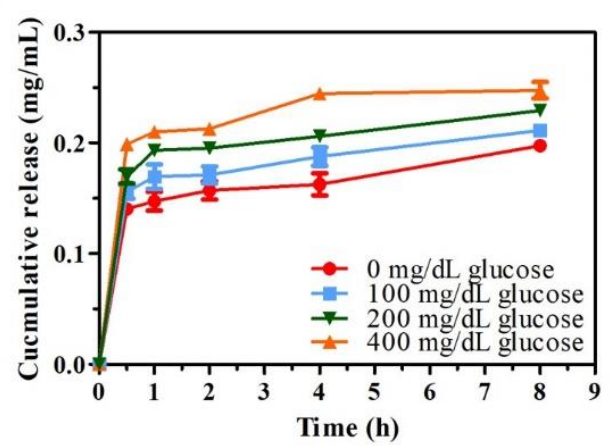

Figure S11. (a) DLS analysis and (b)Glucose responsive insulin release of poly-FG4@insulin (Loading capacity :24.49\%) (poly-G, Mw =46619). Data are average \pm SEM ( $n=3)$ 


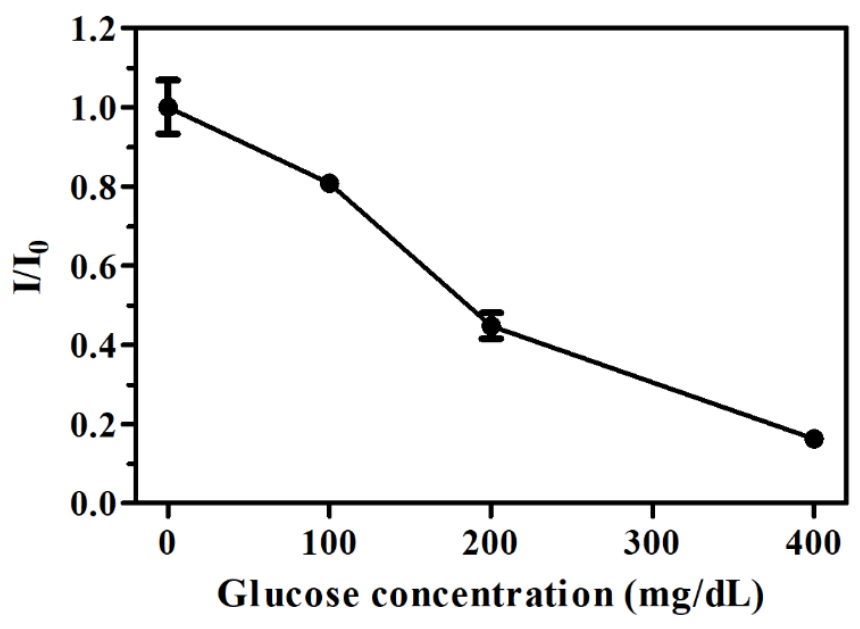

Figure S12. Relative light scattering intensity of poly-FG4@insulin (1 mg/mL) in PBS solutions ( $\mathrm{pH}=7.4)$ with different glucose concentrations. ( $\mathrm{I}_{0}=$ light scattering intensity of samples without adding glucose). Data are average $\pm \operatorname{SEM}(n=3)$ 

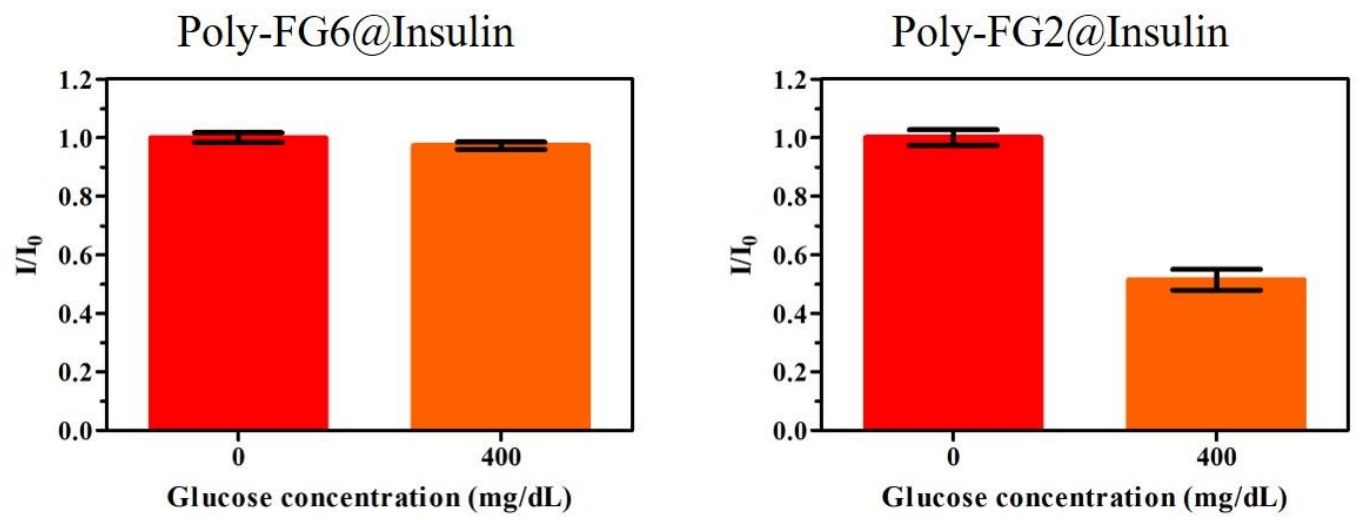

Figure S13. Relative light scattering intensity of poly-FG6@insulin (1 mg/mL) and polyFG2@insulin $(1 \mathrm{mg} / \mathrm{mL})$ in PBS solutions $(\mathrm{pH}=7.4)$ with different glucose concentrations. $\left(\mathrm{I}_{0}=\right.$ light scattering intensity of samples without adding glucose). Data are average \pm SEM ( $n=3$ ) 


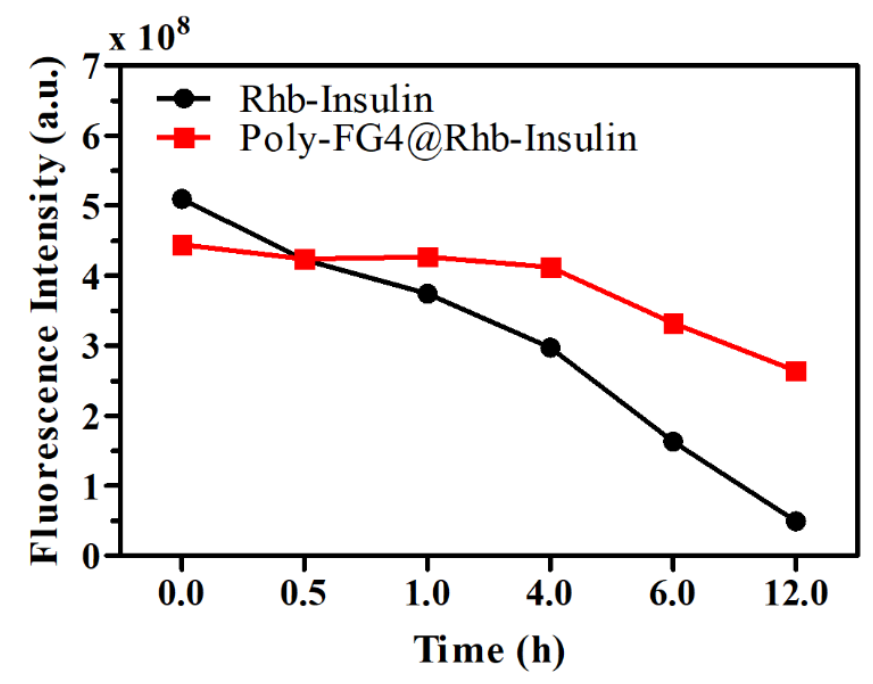

Figure S14. Fluorescence intensity of Rhb-insulin and poly-FG4@Rhb-insulin in diabetic mice at different times. 


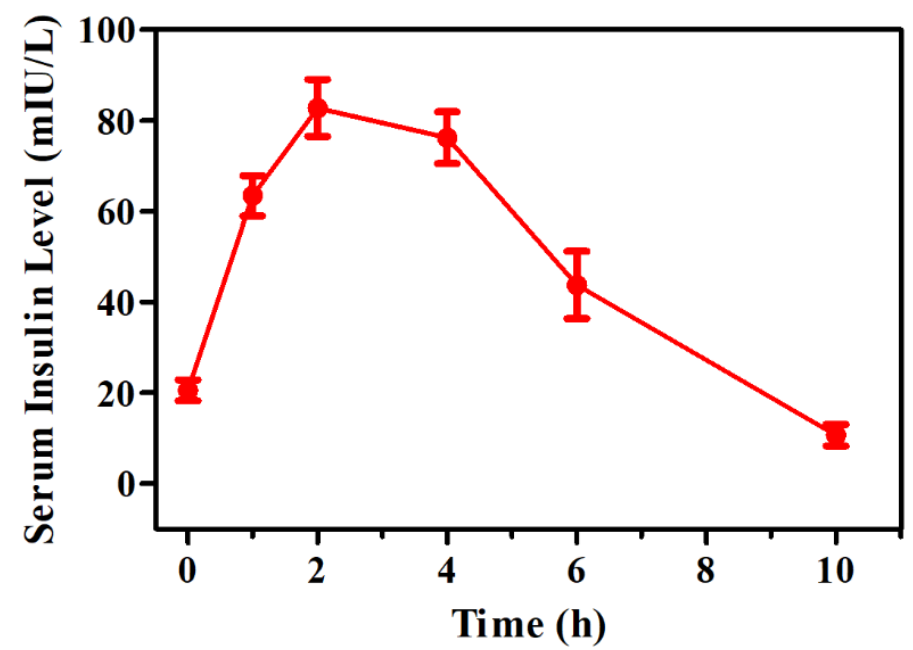

Figure S15. The serum insulin level in diabetic mice treated with poly-FG4@insulin. Data are average $\pm \operatorname{SEM}(\mathrm{n}=3)$ 